\title{
Evaluación de la aplicación del ensayo UMELISA HIV 1+2 RECOMBINANT en muestras de sangre seca sobre papel de filtro $S \& S 903$.
}

\section{Artículo Original}

Enny Morales-Rodríguez, Vivian Alonso-Ramos, Lilliam Pozo-Peña, Aimeé González-Suárez, Yenneby Figueiras-Lache, Adriana González-Quintero, Liliena López-Brauet, Milagros Alvarez-García, Grisell TurróGrau, Deborah Rizo-Polo, Ivonne Gómez-Cordero.

Centro de Inmunoensayo, La Habana, Cuba.

\section{RESUMEN.}

El comportamiento de muestras de sangre seca sobre papel de filtro S \& S 903 (PF S \& S 903) comparado con muestras de suero humano en el ensayo UMELISA HIV 1+2 RECOMBINANT, se estudiaron 318 muestras procedentes de donantes del banco de sangre supuestamente sanos. Se obtuvo como resultado 315 muestras negativas, dos muestras borderline y una muestra positiva. Una vez realizado el DAVIH-BLOT, se confirmó como positiva la muestra positiva obtenida por UMELISA y como negativa e indeterminada las muestras borderline. Con esto se obtuvo un $99.68 \%$ de especificidad.

Con este mismo fin se estudiaron 233 muestras positivas en $\mathrm{SH}$ y $\mathrm{PF} \mathrm{S} \& \mathrm{~S} 903$ a 45 y $55 \%$ de hematocrito, las cuales mantuvieron los mismos niveles de positividad por ambos métodos. Se obtuvo 100 $\%$ de sensibilidad para ambos valores de hematocrito. (Rev Biomed 2004; 15:149-155)

Palabras clave: Papel de filtro, UMELISA, SIDA,
Virus de la Inmunodeficiencia Humana.

\section{SUMMARY.}

Evaluation of the application of the UMELISA HIV 1+2 RECOMBINANT in samples of dry blood on filter paper S \& S 903.

318 samples from supposedly healthy blood donors at the blood bank were studied. As a result, 315 negative samples, two borderline samples, and a positive one were obtained. A DAVIH-BLOT test confirmed the positive, negative and borderline sample obtained by UMELISA. A $99.68 \%$ specificity was obtained with this test. With the same aim in mind, 233 positive samples in SH, FP S \& S 903 to $45 \%$ and $55 \%$ hematocrit were studied. They maintained the same levels of positivity with both methods, and $100 \%$ sensitibity to both values of hematocrit.

(Rev Biomed 2004; 15:149-155)

Key words: Filter paper, UMELISA, AIDS, Human Immunodeficiency Virus.

Solicitud de sobretiros: Lic. Enny Morales-Rodríguez. Departamento de Control de la Calidad, Centro de Inmunoensayo, Calle 134 y Ave.25, Playa, Ciudad de la Habana,Cuba. Tel.208-2928 E-mail: ccinmuno@cie.sld.cu 


\section{E Morales-Rodríguez, V Alonso-Ramos, L Pozo-Peña, A González-Suárez y col.}

\section{INTRODUCCIÓN.}

El Síndrome de Inmunodeficiencia Adquirida (SIDA) es una enfermedad infecciosa de etiología viral, producida por el virus de la Inmunodeficiencia Humana (VIH). Este puede ser trasmitido a través del contacto sexual, la exposición a la sangre o sus derivados o por la utilización de materiales contaminados; se ha demostrado también su transmisión de la madre al feto o al recién nacido durante el período perinatal (1-3).

Las pruebas usadas con mayor frecuencia para diagnosticar la infección por VIH son las pruebas de Ensayo Inmunoenzimático (ELISA) utilizadas para pesquisaje en grandes grupos de muestras, el Western blot como prueba confirmatoria y la Reacción en Cadena de la Polimerasa (PCR) para la detección de carga viral (4)

Desde hace algún tiempo, las muestras de sangre seca sobre papel de filtro han sido empleadas para la detección de hormonas, anticuerpos contra enfermedades infecciosas, drogas, en hemoglobinopatías y recientemente se ha extendido para pesquisaje neonatal, fibrosis quística y la infección por virus de la hepatitis $\mathrm{C}$, para la infección por $\mathrm{VIH}$, así como, para diferentes predisposiciones genéticas (5).

El empleo de muestras de sangre seca sobre papel de filtro ofrece varias ventajas ya que no se necesita un adiestramiento especial para la toma de muestras la cual se hace por punción digital del talón o del lóbulo de la oreja con una lanceta, no hay que centrifugar ni refrigerar las muestras, hay facilidades en el transporte al no existir peligro de derrame del material biológico y las muestras pueden enviarse por correo.

La detección de anticuerpos al VIH por este método se puede utilizar en la certificación de la sangre de donantes y en la vigilancia epidemiológica de la infección por el VIH ya que además, de las ventajas descritas, la infectividad del VIH disminuye en las preparaciones de sangre seca en papel de filtro respecto a las muestras líquidas (6) y los riesgos de adquirir accidentalmente algún agente patógeno presente en las muestras por rotura de la cristalería son eliminados $(7,8)$. Además, se facilita la conservación de las muestras testigo por largos períodos de tiempo, aun si se dispone de escasa capacidad de refrigeración (9).

Disponer de un ensayo que pueda ser aplicado en muestras de sangre seca sobre papel de filtro, constituye un instrumento útil para la realización de estudios en zonas de difícil acceso o en condiciones de escasos recursos instrumentales y carencia de personal adiestrado para la recogida de muestras de suero o plasma.

El UMELISA HIV 1+2 RECOMBINANT es un ensayo inmunoenzimático indirecto, aplicado para la detección de anticuerpos al VIH en suero, plasma, o sangre seca sobre papel de filtro, que emplea, como antígeno de captura proteínas representativas de la envoltura y el cuerpo viral del VIH 1(gp 120, gp41y p24) así como el antígeno gp36 (10), una proteína representativa de la envoltura del VIH 2 obtenidas por métodos recombinantes $(11,12)$; y péptidos sintéticos.

El objetivo de este trabajo fue verificar la especificidad y sensibilidad del ensayo UMELISA HIV 1+2 RECOMBINANT con el empleo del papel de filtro S \& S 903 (PF S \& S 903). Para ello se realizó un estudio comparativo entre las muestras en suero humano y sus homólogas en papel de filtro $S$ \& S 903.

\section{MATERIALES Y MÉTODOS. Colecta de las muestras.}

Durante 6 días se colectaron en tubos de ensayo, $5 \mathrm{~mL}$ de sangre de 318 muestras de donantes pertenecientes a una población supuestamente sana en el Banco de Sangre del Vedado, Ciudad de la Habana, Cuba.

Estas muestras, tanto de suero como de papel de filtro, se enviaron al Laboratorio de Referencia Nacional de Sida (LISIDA) para su confirmación, utilizando como método de confirmación el DAVIHBLOT.

También utilizamos 233 muestras de suero de pacientes seropositivos confirmadas por DAVIHBLOT, procedentes del Sanatorio de VIH Santiago

\section{Revista Biomédica}




\section{Evaluación del ensayo UMELISA HIV 1+2.}

de las Vegas, Ciudad de la Habana, Cuba.

\section{Papel de filtro}

Papel de Filtro S \& S 903 (PF S \& S 903).

\section{Procesamiento de las muestras.}

\section{A.Muestras de suero.}

Las muestras de sangre colectadas en banco de sangre se colocaron a $37^{\circ} \mathrm{C}$ durante 20 minutos para la retracción del coagulo con el propósito de obtener el suero humano de cada una, para su utilización como referencia de las muestras en sangre seca sobre papel de filtro (MSSPF). De esta manera se garantizó que fueran muestras pareadas.

\section{filtro.}

B. Muestras de sangre seca sobre papel de

De las muestras colectadas en Banco de Sangre se dispensaron en las tarjetas de papel de filtro 4 manchas de sangre, de $25 \mu \mathrm{L}$ cada una, que se dejaron secar durante $24 \mathrm{~h}$ entre 20 y $25^{\circ} \mathrm{C}$, con $50 \%$ de humedad relativa.

Previo a la preparación de las muestras en papel de filtro, los eritrocitos fueron lavados con solución salina y filtrados, utilizando para ello una centrífuga Beckman a 2500 rpm.

De las 233 muestras positivas de suero procedentes del Sanatorio, 133 se prepararon como muestras MSSPF al 45\% de hematocrito y 100 al 55\% (MSSPF al 45\% de hematocrito: $100 \mu \mathrm{L}$ de eritrocitos $\mathrm{O}^{+}+100 \mu \mathrm{L}$ de muestra; MSSPF al $55 \%$ de hematocrito: $122 \mu \mathrm{L}$ de eritrocitos $\mathrm{O}^{+}+78 \mu \mathrm{L}$ de muestra).

Posteriormente fueron dispensados de cada muestra 4 discos de $25 \mu \mathrm{L}$ en las tarjetas del papel de filtro S \& S 903 y se dejaron secar durante $24 \mathrm{~h}$ entre 20 y $25{ }^{\circ} \mathrm{C}$, con $50 \%$ de humedad relativa.

\section{Tecnología SUMA.}

Para el análisis de los resultados se empleó la tecnología SUMA compuesta por un Lector PR-521 acoplado a una computadora mediante el cual se realizaron las lecturas de fluorescencia entre los 420 y $540 \mathrm{nM}$ de longitud de onda. La conforman, además, un lavador automático MAS-301, un paquete de programas que realiza la validación, interpretación e impresión de los resultados y los estuches de diagnóstico entre los que se encuentra

\section{el UMELISA HIV 1+2 RECOMBINANT.}

\section{Ensayo UMELISA.}

El UMELISA HIV 1+2 RECOMBINANT es un ensayo inmunoenzimático indirecto, que emplea como fase sólida tiras de ultramicroelisa recubiertas con los antígenos de captura, gp120, gp41, p24, proteínas representativas de la envoltura del núcleo y el cuerpo viral del VIH 1, así como el antígeno gp 36, proteína representativa de la envoltura del VIH 2 , obtenidas por métodos recombinantes y péptidos sintéticos.

\section{Procedimiento Técnico.}

Para las muestras de sangre seca sobre papel de filtro, se perforaron discos de $5 \mathrm{~mm}$ de la zona central de la mancha con el perforador P-51, los que se depositaron en una placa de ELISA. Se les añadió $70 \mu \mathrm{L}$ del diluente del ensayo Tris hidroximetilmetilamina-Carnero y se incubaron una hora a temperatura entre 20 y $25^{\circ} \mathrm{C}$.

A las muestras de suero se les realizó una dilución 1 a 21 con el diluyente Tris hidroximetilmetilaminaCarnero.

Tanto para las muestras de suero como para el eluato de las muestras en sangre seca sobre papel de filtro se tomaron $10 \mu \mathrm{L}$ y se transfirieron a la fase sólida para la realización del ensayo UMELISA.

Las muestras se incubaron 30 minutos a $37^{\circ} \mathrm{C}$ en cámara húmeda. Los anticuerpos IgG presentes en las muestras se fijaron a los antígenos del recubrimiento. Después de 4 ciclos de lavado (de 30 segundos cada uno) con solución reguladora Tris hidroximetilmetilamina $0.0157 \mathrm{M}, \mathrm{pH} 7.8$; se añadieron $10 \mu \mathrm{L}$ del conjugado anti-IgG humana/ fosfatasa alcalina en cada pocillo. Las placas se incubaron como se explicó en la etapa previa y se lavaron nuevamente; posteriormente se adicionaron $10 \mu \mathrm{l}$ de sustrato fluorigénico (4 metilumberilferil fosfato) en los pocillos de la tira y se incubaron durante 30 minutos a temperatura ambiente. La hidrólisis y la intensidad de la fluorescencia emitida por el sustrato permitió detectar la presencia de anticuerpos IgG específicos al VIH 1 y 2 . La lectura, validación e interpretación de los resultados se realizó de forma automática por el lector PR 521 y su 
E Morales-Rodríguez, V Alonso-Ramos, L Pozo-Peña, A González-Suárez y col.

paquete de programas UMELISA HIV $1+2$ RECOMBINANT que realiza el cálculo de relación de fluorescencia según la siguiente fórmula:

$$
\mathrm{Calc}=(\mathrm{Fi}-\mathrm{BB}) /(\mathrm{P}-\mathrm{BB}) \text {. }
$$

Donde: Fi: Fluorescencia de la muestra.

BB: Blanco del ensayo.

P: Control positivo del ensayo.

Se realizó un análisis de correlación, comparando a las muestras ensayadas por suero y papel de filtro, según Zady, 2000 (13) con la determinación de los parámetros estadísticos correspondientes (coeficiente de correlación, pendiente, intercepto y ángulo), además de histogramas de frecuencia, para lo cual se utilizó el programa Microsoft Excel 2000.

Se realizó una prueba paramétrica a las muestras con valores de hematocrito al 45 y $55 \%$. Previo a realizar la prueba fue necesario determinar que fueran muestras aleatorias, que existiera homogeneidad de varianza y normalidad.

El cálculo de la especificidad y la sensibilidad se realizó de la siguiente manera:

$$
\begin{aligned}
& \mathrm{S}=\mathrm{VP} / \mathrm{VP}+\mathrm{FN} * 100 \quad \mathrm{E}=\mathrm{VN} / \mathrm{VN}+\mathrm{FP} * 100 \\
& \text { Donde: }
\end{aligned}
$$

S: Sensibilidad

E: Especificidad

VP: Verdaderos positivos. VN: Verdaderos negativos FN: Falsos negativos.

$$
\text { FP: Falsos positivos }
$$

\section{RESULTADOS.}

\section{Muestras de Banco de Sangre.}

El estudio realizado a las muestras de suero y MSSPF mostró que de un total de 318 muestras de donantes de banco de sangre 315 fueron negativas, 2 borderline y 1 positiva, para un $99,68 \%$ de especificidad.

Estas tres muestras, al ser confirmadas por DAVIH-BLOT, dieron como resultado que la muestra positiva fue verdaderamente positiva y las borderline, una negativa y la otra indeterminada (figura 1).

Como se observa en el cuadro 1 y en el histograma de frecuencia (figura 2), vemos que la relación de fluorescencia es mayor para las muestras

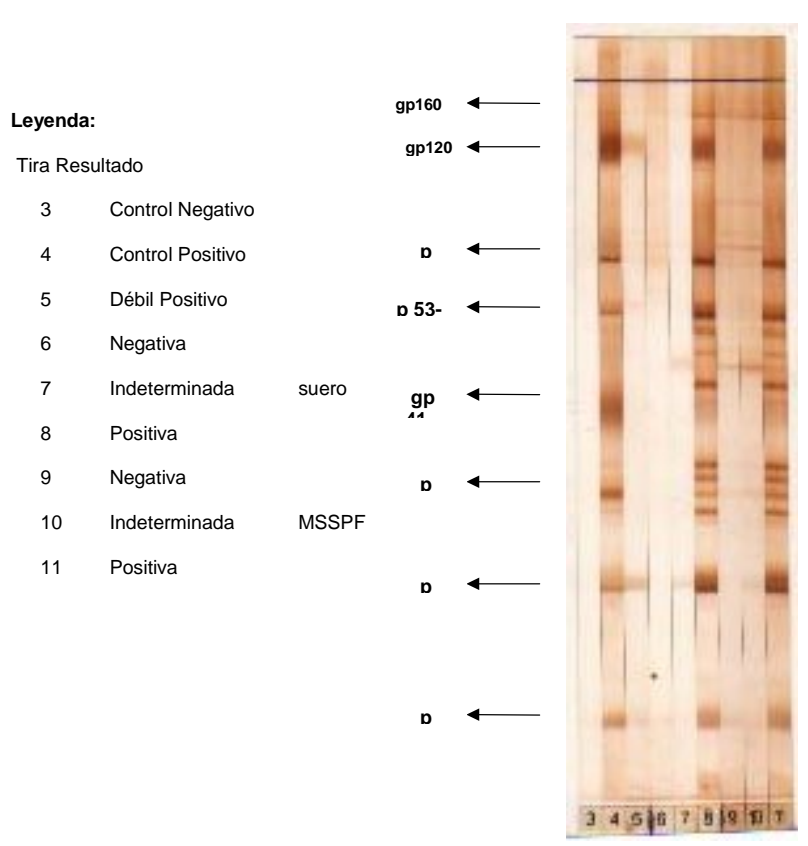

Figura 1.- DAVIH-BLOT de las muestras de Banco de Sangre que resultaron positiva y borderline.

colectadas en papel de filtro que para las muestras de suero.

\section{Muestras positivas del Sanatorio.}

En las 133 MSSPF con hematocrito al $45 \%$ y las 100 con hematocrito al $55 \%$ observamos que la relación de fluorescencia para las muestras colectadas por papel de filtro es mayor que para las muestras de suero (figuras 3 y 4 ; cuadro 1 ).

La sensibilidad de las muestras positivas fue del $100 \%$.

\section{DISCUSIÓN.}

\section{Muestras de Banco de Sangre.}

La clasificación de una muestra como indeterminada fue debido a que sólo presentó como banda la proteína p 24 de núcleo del VIH 1 y, según los criterios de expertos de la Organización Mundial de la Salud (OMS), para que una muestra se considere positiva debe presentar bandas para al menos dos glicoproteínas (14).

El resultado de la confirmación de la muestra positiva por DAVIH-BLOT presentó el mismo

\section{Revista Biomédica}


Evaluación del ensayo UMELISA HIV 1+2.

\section{Cuadro 1 \\ Valores promedio de las relaciones de fluorescencia de las muestras del banco de sangre y de pacientes del sanatorio.}

\begin{tabular}{l|c|cc}
\hline & $\begin{array}{c}\text { Banco de Sangre } \\
\mathbf{n = 3 1 8}\end{array}$ & Muestras Positivas del Sanatorio \\
\cline { 2 - 4 } Muestra & Promedio & $\begin{array}{c}\text { Promedio } \\
45 \% \text { Hematocrito } \\
\mathrm{n}=133\end{array}$ & $\begin{array}{c}\text { P5\% Hedio } \\
\mathrm{n}=100\end{array}$ \\
\hline Papel Filtro & 0.128 & 1.231 & 1.238 \\
Suero & 0.075 & 1.025 & 1.021 \\
\hline
\end{tabular}

patrón de bandas correspondientes al núcleo y la envoltura del VIH 1 y con la misma intensidad tanto para la muestra de papel de filtro como para la de suero. Estos resultaros son similares a los de Teresa y colaboradores en 1995, cuando compararon ambos tipos de muestras por DAVIH-BLOT(15).

Los valores de relación de fluorescencia de las

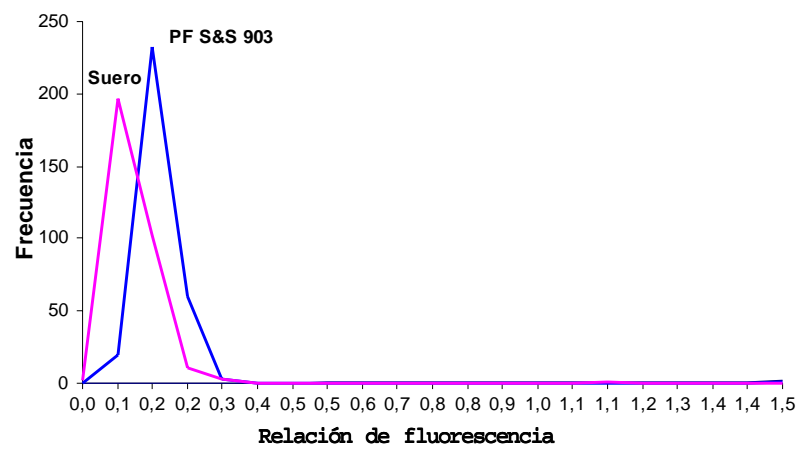

Figura 2.- Histograma de Frecuencias de las muestras de Banco de Sangre.

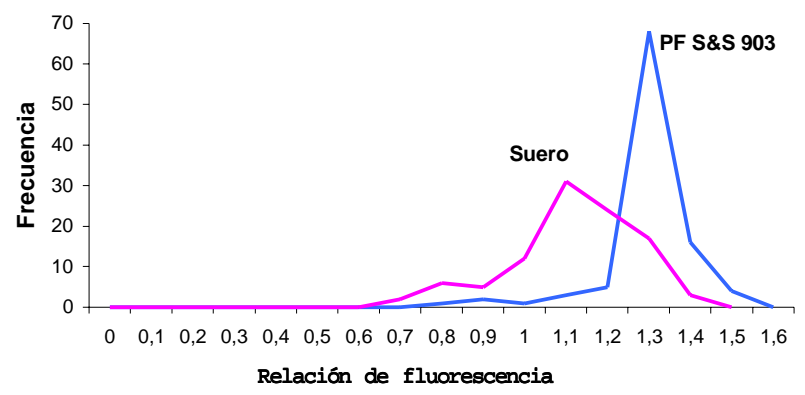

Figura 3.- Histograma de frecuencias de muestras positivas del Sanatorio con hematocrito al $55 \%$. muestras negativas son superiores para las muestras colectadas en papel de filtro con respecto a las muestras de suero, lo cual se debe a la interferencia de los componentes de la sangre total.

Muestras positivas.

Al igual que en las muestras de Banco de Sangre, en las muestras positivas con ambos valores de hematocrito, la relación de fluorescencia es mayor en las muestras de papel de filtro que en las muestras de suero, debiéndose esto también a la interferencia de los componentes de la sangre total.

Como se demuestra en los resultados, la sensibilidad del estuche con las MSSPF fue del $100 \%$, lo que demuestra la utilidad de éste en la detección de anticuerpos al VIH 1 con este tipo de muestra alternativa.

Los resultados de la correlación se muestran

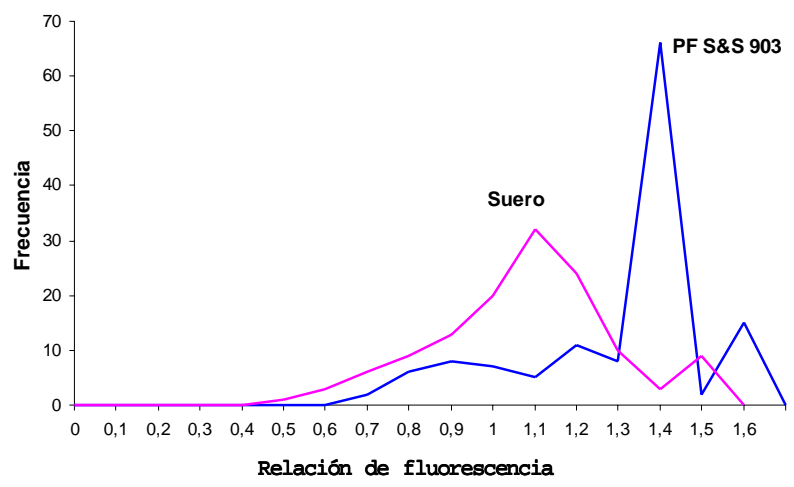

Figura 4.- Histograma de frecuencias de muestras positivas del Sanatorio con hematocrito al $45 \%$. 
E Morales-Rodríguez, V Alonso-Ramos, L Pozo-Peña, A González-Suárez y col.

en el cuadro 2, con el análisis de la comparación entre las muestras de suero y papel de filtro. Observamos que no existen diferencias significativas entre las mismas y por tanto no afecta la sensibilidad y especificidad del ensayo.

Los coeficientes de correlación para las dos muestras se encuentran entre $0.90-1,00$ que son los límites entre los cuales estos coeficientes demuestran una muy alta correlación (15). Este coeficiente representa la fortaleza de la asociación entre las dos variables comparadas (cuadro 2).

\section{Cuadro 2}

\section{Resultados de la correlación entre Muestras de Suero y Muestras de Sangre Seca sobre Papel de Filtro.}

\begin{tabular}{lll}
\hline Parámetros & SS & PF \\
\hline Coeficiente de correlación & 0.98 & 0.97 \\
Intercepto & -1.29 & -10.61 \\
Pendiente & 0.99 & 1.08 \\
Ángulo & $44.71^{\circ}$ & $47.20^{\circ}$ \\
\hline
\end{tabular}

Las muestras con hematocrito al 45 y $55 \%$ cumplieron con los parámetros estadísticos evaluados, pudiendo decir que no existen diferencias significativas entre las dos variantes.

En conlusión, las muestras en sangre seca sobre papel filtro S \& S 903, al ser evaluadas frente a muestras de suero humano no alteran las condiciones de validación ya establecidas para el estuche UMELISA HIV 1+2 RECOMBINANT.

Se obtuvo buena sensibilidad y especificidad para las muestras estudiadas, por lo que se puede utilizar el estuche UMELISA HIV $1+2$ RECOMBINANT, para la detección de anticuerpos al VIH.

\section{REFERENCIAS.}

1.- Desjarlis DC. Antibodies to a retrovirus etiologically associated with acquired inmunodeficiency syndrome (AIDS) in populations with increased incidence of the syndrome. MMWR 1984; 33:377-9.

2.- Ziegler JB. Postnatal transmission of AIDS associated retrovirus from mother to infant. Lancet 1985; 1:896-7.

3.- Gallo RC. Frecuent detection and isolation of cythopathic retroviruses (HTLV-I/II) from patient with AIDS and at risk for AIDS. Science 1984; 224:500-3.

4.- Feinberb MA and Volberding PA. Testing for Human Immunodeficiency Virus. In: Cohen PT, Sande MA, and Volberding PA. The Aids Knowledge Base Boston: Little, Brown and Company, 1994: Section 2.

5.- Roy, R Middendorf. Infrared fluorescent detection of D1S80 alleles from blood and body fluid collected on IsoCode devices. Biotechniques 1997; 23, 942-5.

6.- Chanbancherd P, Brown AE, Trichavaroj R, Tienamporn P, Puthakird P, et al. Application of dried blood spot specimens for serologic subtyping of human immunodeficiency virus type 1 in Thailand. J Clin Microb 1999; 30: 804-6.

7.- Behets F, Kashamuka M, Pappaioanou M, Green TA, Ryder R, et al. Stabilitiy of human immunodeficiency virus type 1 antibodies in whole blood dried on filter paper and stored under various tropical conditions in Kinshasa, Zaire. J Clin Microb 1992; 30:1179-82.

8.- Van den akker B. Recovery of HIV antibodies in eluates from plasma and erythrocytes dried on filter paper and stored under various conditions. AIDS 1990; 4:87-92.

9.- Evengaard B.Effect of heat on extracted HIV infectivity and antibody activity using the filter paper technique of blood sampling. AIDS 1989; 3:391-5.

10.- Novoa LI. Cloning and expression of the major core HIV-1 protein in bacteria. $1^{\text {er }}$ Congreso Iberoamericano de Biotecnología. Libro de Resúmenes (s05-051). La Habana, Cuba, 1989.

11.- Novoa LI. Development of a system for HIV seroconversion using two recombinant antigens. International Biotechnology Congress. Paris, 1988.

\section{Revista Biomédica}


12.- Silva C. UMELISA con antígeno recombinante para el pesquisaje de anticuerpos Anti-VIH. III Reunión Iberolatinoaméricana de Hematología. Libro de Resúmenes, La Habana, Cuba. 1989. p. 203.

13.- Zady M. Correlation and simple least squares regression. Clinical Laboratory Science Program, University of Louisville. Louisville, Kentucky; 2000.

14.- World Health Organization. Proposed WHO criteria for interpreting results from western blot assays for HIV-1, HIV-2 and HTLV-I/II. Wkly Epidemiol Rec, 1990; 65:283-8.

15.- Weiss SH. Laboratory detection of human retroviral infection. In: Wormser GP. AIDS and Other Manifestations of HIV Infectation. New York: Lippincott-Raven;1998. p. 175-200. 